\title{
Research on Strategy of Model Innovation of WeChat Marketing
}

\author{
Ping Zhang \\ College of Mobile Telecommunications, Chongqing University of Posts and Telecom, Chongqing \\ 401520, China \\ jameszp@foxmail.com
}

Keywords: WeChat, marketing, model innovation, Strategy.

\begin{abstract}
Network develops rapidly these years along with the continuous development of network technology revolution. The network nascent product "WeChat" rises to fame quickly in cyberspace, and businesses discover a new way of marketing in the internet "tide player" - Wechat marketing. Wechat marketing is an integration product of today's rapidly developing market economy and network economic; it is an important research topic in today's disciplines of economics, management science, etc. Based on this, this paper on the foundation of analyzing the basic connotation and characteristics of Wechat marketing focuses on analysis of the Wechat marketing's innovation model, in order to enlighten the relevant personnel.
\end{abstract}

\section{Introduction}

Wechat marketing is an integration product of today's rapidly developing market economy and network economic, and is an important research topic in today's disciplines of economics, management science, etc. WeChat is on the network, there is no distance limitation between business sellers and consumers, once the users register WeChat, can form links with other users. Through this connection, consumers can have timely access to business products' information; also can timely communicate feedback quality of relevant products, after - sales service and other issues to management sellers. With the rapid development of e-commerce, Wechat marketing today has gradually become the most important part of e-commerce, operational sellers through providing product information needed by consumers, in the process of promoting their products, also learn the market and the consumers' needs, then realize the "point to point" service between operational sellers and consumers[1].Therefore, the analysis of Wechat marketing model also has very important significance. Today, the rapid development of the network, along with the continuous development of network technology revolution, network nascent product "WeChat" rise to fame quickly in cyberspace. Merchants are seeing this point, to seize business opportunities, discover a new way of marketing in this internet "tide player" - Wechat marketing.

\section{Connotation Definition and Characteristics of Wechat marketing}

1) Definition of network marketing. Network marketing is the business activity based on modern marketing theory, through the network, communications and digital media technology to achieve marketing objectives, is contributed by the scientific and technological progress, changes in customer value, market competition and other combination factors, is the inevitable product of the information society[2]. There are broad and narrow network marketing in accordance with its implementation, the broad Network marketing refers to enterprise use all computer networks (including Intranet, EDI and Internet) to carry out marketing activities. The narrow network marketing specifically refers to internet marketing (Internet, the world's largest computer network system). means the whole process of the organizations or individuals base on the convenient internet to make a series of business activities for products, services, so as to achieve to meet the needs of organization or individual, network marketing is an integral part of their overall marketing strategy, is a marketing tool built on the basis of internet via the internet's characteristics to achieve certain marketing objectives[3]. 
2) Definition of Wechat marketing. Currently, there is not a complete and unified definition on Wechat marketing model. And in today of marketing diverse development, through WeChat network for marketing has gradually become a new marketing model. And micro-blog marketing has the same purpose with Wechat marketing, is generally known [4]. The CEO of NITC web marketing service center, LIAO Hongfa said: "micro-blog marketing influence is worth, is insightful, is interpersonal_first learn marketing the influence ourselves, product marketing can be more effective." This paper argues that Wechat marketing and micro-blog marketing are both through the network platform using various resources to undertake a series of marketing activities, through the embedded advertising style of product, those who have purchased feedback so as to achieve the branding publicity of the selling products, as well as through the network to build a new customer service platform. Wechat marketing is mainly reflected in through mobile clients installed in the mobile phone or tablet with android system, apple system, windowsphone8.1 system to carry out area targeted marketing, business man through WeChat public platform to show micro official website, micro membership, micro push, micro-payment, micro activity, micro CRM, micro statistic, micro stock, micro commission, micro reminder, there has been formed a mainstream online underline WeChat interactive marketing.

3) Characteristics of Wechat marketing. Wechat marketing is a new and unique e-commerce marketing, the breadth of its information network, the shortcut of information dissemination, three-dimension of product promotion, interpersonal interaction, etc., all have their own unique characteristics[5][6].(1)The extension of information network. Because WeChat registration process is very simple, either real name, or you can also set up a network nickname with product features, product information pass through mutual concern between the WeChat friends circle, and the impact is very extensive.(2)The rapidity of information dissemination. Wechat marketing is superior to traditional advertising in the information publishing process, eliminates complicated approval procedures, and also eliminates large sums of shooting advertising costs, because the users' feedback is the best advertising. So through WeChat to advertise often is able to reflect the information of selling products in the first time. (3)Three-dimensional of product promotion. Currently, the multimedia technology develops rapidly, merchants in WeChat platform with words and pictures to publicize or with a network connection to a specific online shop, provide for consumers visualize specific varied forms to display the selling goods.(4)Interpersonal interaction. The commodity information released by WeChat network platform can be direct communication with consumers in the form of text or voice in the first time, solve the problem of businessman due to cannot timely communication with consumers then lose customer base; meanwhile, the more timely product information publication, the more resonation or disputation of consumers, through feedback, the more they can cause everyone's attention, the greater the range of information transfer[7] [8].

\section{Analysis of Wechat marketing Model Innovation}

1) Grass-roots advertising style-view nearby person. (1)Product description: Signature column is a major feature of Tencent product, users can update status in their signature columns, naturally you can make the mandatory advertising, but only the user's contacts or friends can see. The WeChat functionality plug-in " Browse nearby person " based on LBS can make more strangers to see the mandatory advertising. (2) Function mode: After click the "Browse nearby person", the users can find the around WeChat users based on their geographic location. In these vicinity WeChat users, in addition to display the user's name and other basic information, also display the contents of the users' signature. So users can take advantage of this free advertising place to advertise their products.(3) Marketing style: Marketing personnel in the most flow place use WeChat 24 hours, if there are enough users click " Browse nearby person ", the advertising effect will rise with the number of WeChat users rises, it is possible this simple signature column may become a movable "golden advertising" [9].

2) Brand activity type-drift bottle. (1)Product description: Drift bottle is an application transplanted to QQ e-mail, this computer application is widely acclaimed, and many users prefer this 
simple and interactive way with stranger. After ported to WeChat, the drift bottle function generally retains the original style simple and easy to use. (2)Function mode: Drift bottle has two simple functions: First is "throw one", users can choose to publish a voice or text and then click "throw into the sea"; second is "pick up one", after "salvage" the drift bottle threw by countless users in the sea, then can dialogue with the thrower, but each user has only 20 chances one day. (3)Marketing style: The WeChat official can change the parameters of drift bottle, and make the number of drift bottles about the cooperation business promotion activities thrown in a period time significant increase, the frequency salvaged by ordinary users also increase. Plus drift bottles mode itself can send different texts or even a voice game and so on, if marketing properly, can produce a good marketing result. And this voice mode makes users feel more real. But if only pure advertising slogan, it may cause users' objection [10].

3) O2O discount type-scan the two-dimensional code.(1)Product description: "Scan QR Code" This function was originally a reference of another foreign social tool "LINE", through scanning to identify another user's identity of two-dimensional code, so as to add friend. But today with the two-dimensional code development, its commercial use is more and more extensive, therefore WeChat follow this trend, combine $\mathrm{O} 2 \mathrm{O}$ to undertake business activities.(2)Function mode: put the two-dimensional code pattern into the frame, and then you will be able to get a member discount, business discount or some news information.(3)Marketing style: plug scanning two-dimensional code in mobile application, this $\mathrm{O} 2 \mathrm{O}$ style is already popular; WeChat has a million users with active degree high enough, its value is self-evident[11].

4) Interactive marketing type-WeChat public platform. (1)Product description: For the popular media, celebrity and enterprise, if the open of WeChat open platform + sharing function in friend circle has made $\mathrm{WeChat}$ to be a marketing channel cannot be ignored in the mobile internet, then WeChat public platform make this marketing channel more granular and direct.(2)Function mode: through push and attention by one to one, public platform push news, product information, latest events, etc. to fans, and even be able to provide functions including consult, customer service, and so on, become one qualified CRM system. You can say that the on-line of WeChat public platform provide a mobile website based on billions of WeChat users.(3)Marketing style: by publishing two-dimensional code of the public account, make WeChat users can subscribe to the public platform account conveniently, and then after grouping the users and geographic control, public platform can push precise message directly to the target users. The following is through personal attention page and friends circle to achieve brand's viral spread [10].

5) Social sharing type-an open platform + friends circle.(1)Product description: WeChat open platform is a new feature introduced in version 4.0 of WeChat, application developers can plug in third-party applications through the WeChat open interface. Applications' LOGO can also be placed in WeChat attachment field, allow WeChat users to invoke third-party applications, to select and share content easily in the session. (2)Function mode: Social sharing has been a hot topic in the e-commercial. In the mobile internet, take the partner before announced by Tencent as an example, the WeChat users spread commodities on the Meitu one by one, to achieve the most direct mouth marketing on social media. (3)Marketing style: In addition to WeChat asynchronous communication features, the open of share function in friends circle, the new feature in version 4.0, offer the best channel for sharing type mouth marketing. WeChat user can directly share mobile phone application, $\mathrm{PC}$ client, the compelling content on website in friends circle, and support opening through website links[10].

6) Network operational type-WeChat shop. This WeChat shop (WeChat Mall) is not Tencent self-operational platform, the upgrade of WeChat selection product channel, but is after merchant apply for permission to pay and then create platform for WeChat shop. By the end of 2013, if the public account want to apply for permission to WeChat payment, need to accord with two conditions: first must be service number; second still need to apply for WeChat certification to obtain WeChat's high-level interface permissions. Only after merchant applied for WeChat payment, can further make use of WeChat's open sources to establish WeChat shop[10]. 


\section{Summary}

WeChat marketing is kind of marketing business model in network economic time, is a type of network marketing accompanied by fame WeChat to emerge[12]. In WeChat do not exist distance limitation, after register in WeChat, the user can form a contact with the around "friends" also have registered, subscribe to the information they need, merchants through providing information users need to promote their products, realize point to point marketing. WeChat marketing network, the new type of e-commerce marketing can become the mainstream model of future society, is an effective force and weapons to corporate's brand marketing and personal marketing. Only learn to use the power of Wechat marketing, make the brand more dynamic, can bring more convenience to people's live and work.

\section{References}

[1] Wen Danfeng, WeChat Marketing: Weapon on the Fingertip , Beijing: People Post Press, 2013.

[2] Feng Yingjian, The Foundation and Practice of Internet Marketing, Beijing: Tsinghua University Press, 2002.

[3] Shao Yuxia, The exploration of network marketing communication model in new media era , Enterprise Technology Development,2010(06).

[4] Han Yang, How Merchants Bank utilizes WeChat?, Business Value, 2013(06).

[5] Zhang Yanhong, Analysis of WeChat application in enterprise network marketing, China Trade, 2013(28).

[6] Ou Zhiming, Application of WeChat public platform in enterprise network marketing, New Marketing, 2014(06).

[7] Fang Xingdong, etc., Research on WeChat propagation mechanism and governance issue, Modern Media, 2013(06).

[8] Dang Haoqi, Deconstruction WeChat information dissemination model from the perspective of Communication Science, Southeast Spread, 2012(07).

[9] Tan Kai, Pros and cons of WeChat in enterprise marketing, New Marketing, 2012(11).

[10] Shao Xiaotong, Pros and cons of WeChat in enterprise marketing, New Marketing, 2012(11).

[11] Yan Xue, Application prospects of $\mathrm{O} 2 \mathrm{O}$ business model in the scenic area marketing, Tourism Overview, 2013(02).

[12]Wang Xia, The new marketing model and strategy based on WeChat, Management Observe, 2013(08). 